\title{
Evaluation of the Cytotoxic Effect of Rutin Prenanoemulsion in Lung and Colon Cancer Cell Lines
}

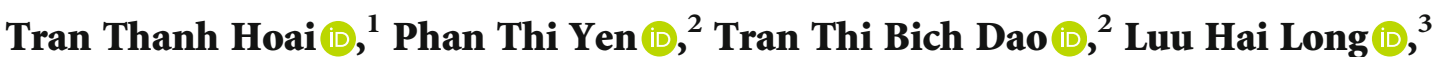 \\ Duong Xuan Anh $\mathbb{D}^{3},{ }^{3}$ Luu Hai Minh $\mathbb{D}^{\mathbb{D}},{ }^{2}$ Bui Quoc Anh $\mathbb{D}^{2},{ }^{2}$ and Nghiem Thi Thuong $\mathbb{D}^{1}$ \\ ${ }^{1}$ School of Chemical Engineering, Hanoi University of Science and Technology, Hanoi, Vietnam 10000 \\ ${ }^{2}$ Nhathai New Technology JSC, Hoang Mai, Hanoi, Vietnam \\ ${ }^{3}$ Faculty of Biotechnology-Agricultural Academy, Hanoi, Vietnam
}

Correspondence should be addressed to Nghiem Thi Thuong; thuong.nghiemthi@hust.edu.vn

Received 27 August 2020; Revised 20 October 2020; Accepted 24 October 2020; Published 18 November 2020

Academic Editor: Anuj Kumar

Copyright (C) 2020 Tran Thanh Hoai et al. This is an open access article distributed under the Creative Commons Attribution License, which permits unrestricted use, distribution, and reproduction in any medium, provided the original work is properly cited.

\begin{abstract}
In this work, prenanoemulsion of rutin was prepared using PEG and Tween as emulsifiers via homogenization and evaporation techniques. The particle size of rutin was investigated with high-resolution transmission electron microscopy (HR-TEM); particle size distribution and its chemical structure were analysed by nuclear magnetic resonance (NMR) and Fourier transformed infrared (FT-IR) spectroscopy. It was found that rutin in the prenanoemulsion has excellent solubility in water with the size approximately $15 \mathrm{~nm}$. The chemical structure of nanorutin in prenanoemulsion was identical to that of the pure rutin. It suggested that there is no chemical modification of rutin in the prenanoemulsion. From high-performance liquid chromatography (HPLC), the amount of rutin in the prenanoemulsion was determined to be $9.27 \%$. The cytotoxic effect of rutin in the preemulsion was investigated via in vitro tests to determine rutin's efficacy in A549 lung cancer cell and colon cancer cell treatment. The results demonstrated that rutin in the prenanoemulsion could inhibit A549 lung cancer cells and colon cancer cells efficiently.
\end{abstract}

\section{Introduction}

Rutin (3,3' $4^{\prime}, 5,7$-pentahydroxyflavone-3-rhamnoglucoside) whose chemical structure is shown in Figure 1 is a flavonol, which is plentifully found in many typical plants such as passion flowers, buckwheats, black teas, and apples. It has diverse biological activities and pharmacological applications, i.e., antioxidation, antitumor, anti-inflammatory, antivirus, and low toxicity with potential clinical applications [1]. Amongst all the applications, the anticancer effect of rutin has been extensively investigated. Lin et al. reported that rutin with the dose of $120 \mathrm{mg} / \mathrm{kg}$ caused a significant reduction in the tumor size of the murine model implanted human leukemia HL-60 cells [2]. From the study on the LAN-5 neuroblastoma cell line, rutin showed the capability of decreasing levels of MYCN mRNA, the secretion of
TNF- $\alpha$, and reducing BLC2 expression as well as BCL2/BAX ratio [3]. Besides, rutin also showed its effect on many other cancer cell lines such as CRC colorectal cancer cells, B16F10 lung cancer cells, and HTC liver cancer cells. It was demonstrated that rutin affected the cell capture and apoptosis processes, reducing the number of metastatic nodules and cytotoxicity [4-6]. However, rutin was slightly absorbed in the gastrointestinal tract due to the poor water solubility $(0.8 \mathrm{mg} / \mathrm{mL})$ [7]. Hence, the oral bioavailability of rutin is rather low (around 20\%) [8].

Numerous approaches have been investigated to improve the bioavailability of rutin. These approaches include the preparation of nanoparticular systems [9-13], nanophytosome [14], and cyclodextrin complexes $[15,16]$. Recently, nanoparticlebased drug delivery systems have been further utilized in cancer treatment. The advantages of the nanoparticle-based drug 
<smiles>C[C@@H]1OC(OC[C@H]2OC(Oc3c(-c4ccc(O)c(O)c4)oc4cc(O)cc(O)c4c3=O)[C@H](O)[C@H](O)[C@H]2O)[C@H](O)[C@@H](O)[C@@H]1O</smiles>

Figure 1: The chemical structure of rutin [26].

delivery systems are that nanoparticle drugs could be designed to achieve longer circulation time, better stability, more improved internal medicine accumulations and concentrations, and better ability of reducing the toxicity to normal tissues [17]. Nanoparticle-based drug delivery systems (such as nanoemulsion, liposomes, prenanoemulsion, niosomes, and nanoparticles) are commonly stabilized with surfactants or polymers [18]. Recently, the prenanoemulsion drug delivery system has been emerging as one of the most interesting approaches to improve the poor solubility of drugs. Prenanoemulsion is a mixture composed of surfactants, cosurfactants, and drug substances, which can form a nanoemulsion under conditions of gastrointestinal fluids and gastrointestinal motilities after the oral administration. It was noted that prenanoemulsion does not contain water and thus its physical and chemical stability lasts longer than those in nanoemulsion [19]. The formation of rutin in nanoemulsion with a particle size less than $100 \mathrm{~nm}$ could enhance the solubility and the absorption of drugs in the gastrointestinal tract [20]. The solubility and stability of the prenanoemulsion system closely depend on screening surfactants such as Tween-80, Labrasol, Cremophor RH 40, and Kolliphor-HS15 together with other cosurfactants, i.e., Carbitol, Transcutol-P, and polyethylene glycol- (PEG-) 200, 400, and 600 [21]. The selection of the excipients for the preparation of the prenanoemulsion as anticancer drug delivery systems must ensure that the system should have long-standing stability, a long circulation time, and the ability to increase the drug accumulation in cancer cells. Another requirement is that the system should not be toxic to normal cells.

Rutin is widely acknowledged for good solubility in Tween-80 and PEG-600 [21]. Tween-80 is a nonionic surfactant which is well known for its hydrophilicity and biodegradability. It exhibits no toxicity for cell at low concentration [22]. Previous works showed that Tween-80 has the ability to inhibit the mononuclear phagocyte systems and prolong the circulation time of the nanoparticles which then extend drug release times [23, 24]. PEG, on the other hand, is a polymer possessing hydrophilicity, biocompatibility, and nonallergenicity. It plays a role as a good stabilizer for the colloidal system $[24,25]$. Therefore, in this study, Tween-80 and PEG-600 were selected as the excipients for the preparation of prenanoemulsion of rutin. To the best of our knowledge, there is few research on the formulation of rutin in the preemulsion system and its cytotoxicity on lung and colon cancers [21]. The aim of our study is to assess the cytotoxic effect of the prenanoemulsion system of rutin in lung cancer (A549) cells, colon cancer (Caco-2) cells, and HDF human fibroblast cells. The rutin in the prenanoemulsion system containing Tween-80 and PEG-600 was prepared with the optimal formulation of substances. The efficacy in anticancer treatments and the safety of fabricated rutin prenanoemulsion were evaluated through the MTS assay. In the in vitro test, the lung cancer (A549) cells, colon cancer (Caco-2) cells, and HDF human fibroblast cells were treated with the rutin prenanoemulsion, pure rutin, and the excipients (mixture of Tween-80 and PEG-600), respectively.

\section{Materials and Methods}

2.1. Materials. Rutin was provided by Tokyo Chemical Industry Co., Ltd. (APAC). Ethanol (99.8\%) and polyethylene glycol with a molecular weight of $600 \mathrm{~g} / \mathrm{mol}$ (PEG-600) were supplied by the NOF Corporation of Shibuya-Ku, Tokyo. Tween-80 was provided by INEOS Oxide (Lavéra France). DMEM (Gibco), CellTiter $96^{\circledR}$ AQueous One Solution Cell Proliferation Assay (MTS) (Promega), and fetal bovine serum (FBS) and penicillin-streptomycin (PS) were supplied by Sigma-Aldrich. All reagents were analytical grade and used as being received without further purification.

The cell lines used in the in vitro tests were included lung cancer (A549) cell lines, colon cancer (Caco-2) cell lines, and HDF human fibroblast cell lines provided by ATCC.

\subsection{Methods}

2.2.1. Preparation of the Rutin Prenanoemulsion Drug Delivery System. A solution of rutin was prepared by dissolving rutin in ethanol at the concentration of $0.02 \mathrm{~g} / \mathrm{mL}$ and stirring at $400 \mathrm{rpm}$ for 10 minutes at room temperature. PEG-600 and Tween-80 were then added to the solution at a ratio $10 \% \mathrm{w} / \mathrm{w}$ and $30 \% \mathrm{w} / \mathrm{w}$, respectively. The rutin prenanoemulsion system was maintained at $60^{\circ} \mathrm{C}$, mixed at $400 \mathrm{rpm}$ by using a magnetic stirrer for 30 minutes, and continuously dispersed using the ultrasonicator. The prenanoemulsion system was left overnight at room temperature then homogenized for 60 minutes at a normal condition. After that, the prenanoemulsion system was evaporated for 60 minutes at $50^{\circ} \mathrm{C}$ to remove residual ethanol. Finally, it was stored at room temperature for further analysis.

2.3. Characterizations. The water solubility of the rutin prenanoemulsion was tested by the Tyndall effect. Rutin preemulsion dispersion and rutin dispersion were prepared by adding the same amount of the prenanoemulsion of rutin and pure rutin into two beakers containing water. The redwavelength laser was beamed through each dispersion, and the photographs were taken.

The morphology of the rutin in the water dispersion was observed using the transmission electron microscopy (TEM) (JEOL Co., JEM-2100, Tokyo, Japan) at an acceleration voltage of $200 \mathrm{kV}$. The prenanoemulsion of rutin was dispersed in water and then dropped into a specimen. The specimen was dried in a vacuum oven before observation. The average size of the rutin nanoparticles in the suspension was also estimated. 
The particle size distribution of rutin prenanoemulsion was determined by a dynamic laser scattering technique (DLS) using Horiba SZ-100. The sample was diluted with water to a suitable concentration, and the measurement was carried out at a scattering angle of $90^{\circ}$ at room temperature three times.

The FTIR of rutin prenanoemulsion, pure rutin, PEG, and Tween- 80 were recorded on the JASCO 4600 spectrometer in the range of $4000-400 \mathrm{~cm}^{-1}$ with a resolution of $4 \mathrm{~cm}^{-1}$. The number of scans is 64. All FTIR measurements were performed at room temperature.

The NMR measurements of samples were performed with the JEOL FT-NMR $400 \mathrm{MHz}$ (Japan). The samples were dissolved in methanol-d4 and subjected to the measurement with 128 scans. The chemical shift is referenced with the proton signal of methanol-d4.

The amount of the rutin in the rutin prenanoemulsion was determined by the HPLC equipped with UV detected. Chromatographic conditions used the Agilent Zorbax Eclipse XDB C18 column $(150 \times 4.6 \mathrm{~mm} ; 5 \mu \mathrm{m})$, ultraviolet spectrophotometer at $257 \mathrm{~nm}$, and mobile phase: methanol$1 \%$ acetic acid solution $(40: 60, v / v)$. The method has a linear range of $4.97-298.47 \mu \mathrm{g} / \mathrm{mL}$, limit of quantity $0.205 \mu \mathrm{g} / \mathrm{mL}$, and recovery from $99.87 \%-102.3 \%$.

2.4. Cell Viability Assay Test. The cell viability was determined to compare the cytotoxic of pure rutin and rutin prenanoemulsion in A549 lung cancer cells, Caco-2 colon cancer cells, and HDF human fibroblasts after the MTS assay. The cells were seeded in 96-well microtiter plates at a density of 5000 cells/well in Dulbecco's modified Eagle's medium (DMEM). The mediums were supplied with $10 \%$ fetal bovine serum (FBS) and $1 \%$ penicillin-streptomycin (PS) and were maintained in a humidified incubator containing $5 \% \mathrm{CO}_{2}$ at $37^{\circ} \mathrm{C}$ for 24 hours. After being seeded, the cells were treated with various pure rutin concentrations, prenanoemulsion rutin, excipients, control vehicle solution (DMSO $0.1 \%$ in phosphate buffer saline), or control solutions (culture medium without test sample and DMSO). Seventy-two hours after the treatment, $20 \mu \mathrm{L}$ MTS was added to a culture medium, and incubation was continued at $37^{\circ} \mathrm{C}$ for 4 hours. The color intensity was measured at $490 \mathrm{~nm}$ with an ELISA microplate reader (BioTek Synergy ${ }^{\circledR}$ HT microplate reader (USA)). The experiments were performed in triplicate.

A549 lung cancer cells were incubated with multiple concentrations of samples of $30,50,100,150,200$, and $300 \mu \mathrm{M}$.

Caco-2 colon cancer cells were incubated at various concentrations of samples of $20,30,50,100,150,200$, and $300 \mu \mathrm{M}$.

HDF human fibroblast cells were incubated at a range of concentrations of samples from 50 to $300 \mu \mathrm{M}$.

The MTS assay is based on the conversion of MTS substrate [3-(4,5-dimethylthiazol-2-yl)-5-(3-carboxymethoxyphenyl)-2-(4-sulfophenyl)-2H-tetrazolium] into MTS-formazan by the dehydrogenase respiratory enzyme in the mitochondria of living cells. The MTS-formazan solution that dissolves in the culture medium has a blue-violet color and maximizes the absorption at $490 \mathrm{~nm}$. The number of living cells is directly proportional to the formazan concentration, expressed in the solution's optical density value at $490 \mathrm{~nm}$.

The percentage of living cells determined from OD490 values was obtained using the following equation:

The percentage of living cells $(\%)=\frac{\text { OD490 }(\text { sample })-\text { OD } 490(\text { blank })}{\text { OD } 490(\text { control })-\text { OD } 490(\text { blank })} \times 100 \%$.

2.5. Statistical Analysis. All the results were presented as \pm standard error of the mean value. Statistical analysis was performed using ANOVA. A value of $p<0.05$ was considered statistically significant.

\section{Results and Discussion}

3.1. Characterizations. The screening formulation of the prenanoemulsion system was usually considered involving the following factors. First, the formulation composition should be simple, safe, and compatible. Second, the formulation should have good solubility and effective droplet size after forming a microemulsion $[27,28]$. The selection of the surfactant/cosurfactant mixtures was primarily considered for the homogeneity of the system. This is much related to the Hydrophilic-Lipophilic Balance (HLB) of the surfactant. The surfactants with HLB of 12-15 are good choices for the best efficiency. Tween- 80 with HLB of 15 combined with PEG-600 as cosurfactant can adjust the HLB of surfactant and increase the stability of microemulsion and enhance the solubility of hydrophobic drug [29]. Therefore, the excipients, Tween-80 and PEG-600, were chosen to load rutin in the preemulsion system. Several formulations were performed to evaluate the formation of prenanoemulsion of rutin. The best results were obtained with PEG-600 and Tween-80 at a concentration of $10 \% w / w$ and $30 \% w / w$, respectively. We used this formulation of rutin preemulsion for further studies.

The solubility of prenanoemulsion of rutin in water is assessed indirectly through dispersing of preemulsion into the water and observed the light scattered through the dispersion, that is, the Tyndall effect.

The Tyndall effect is a phenomenon which is based on the light scattering caused by particles in colloidal or suspension. This effect is employed to verify scattering ray caused by particles in the colloidal or suspension and assess the homogeneity of the solution from the scattering [30]. When the beam of light with a wavelength in the range of 630-680 nm went through liquid-containing particles with the size from 40 to $900 \mathrm{~nm}$, these particles scatter the ray; thus, they become brighter spots which can be observed [30]. The image of the Tyndall effect of the two dispersions containing pure rutin and rutin in the prenanoemulsion is presented in Figure 2. The observed results indicated that rutin in the preemulsion with PEG/Tween was well dispersed in water.

The morphology of rutin particle in the prenanoemulsion is investigated and shown in Figure 3. The rutin nanoparticles had a spherical shape with a smooth surface. The rutin particles were uniform in size and shape and distributed evenly in the water emulsion. The average size of the rutin 


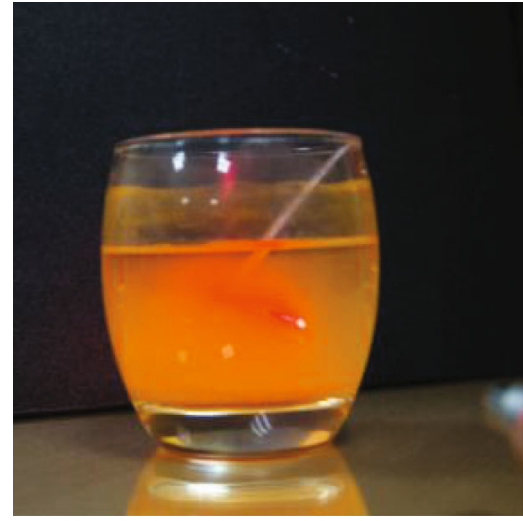

(a)

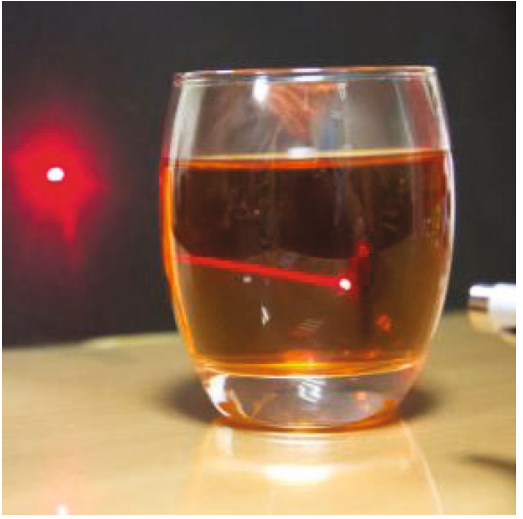

(b)

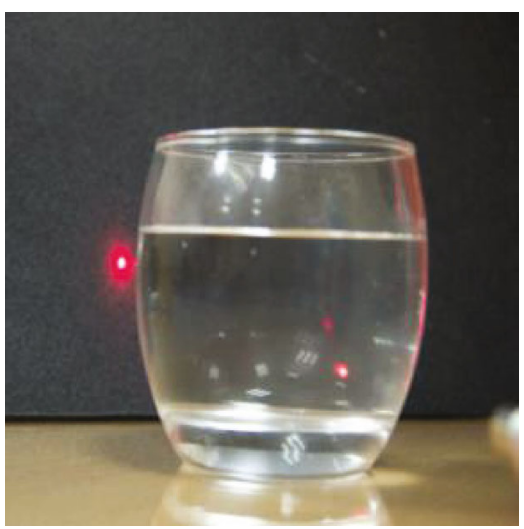

(c)

Figure 2: The Tyndall effect of (a) rutin in water, (b) prenanoemulsion of rutin in water, and (c) pure water.

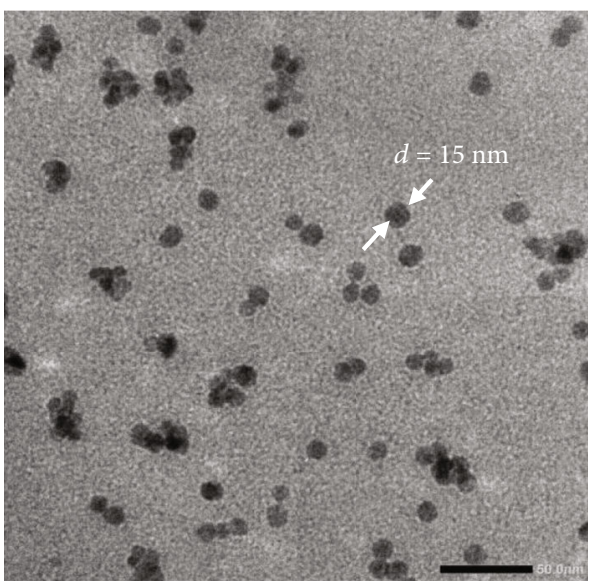

FIGURE 3: The HR-TEM image of nanorutin after dissolving the preemulsion in water.

nanoparticles was about $15 \mathrm{~nm}$. Previous studies [31-33] have shown that nanoparticles with size ranging from 10 to $100 \mathrm{~nm}$ are suitable for drug delivery in the body. Nanoparticles with a size larger than $10 \mathrm{~nm}$ will not be leaked into capillaries and will then be removed by single-pass renal clearance. Nanoparticles with size less than $100 \mathrm{~nm}$ can escape from being captured by the macrophage in the mono-

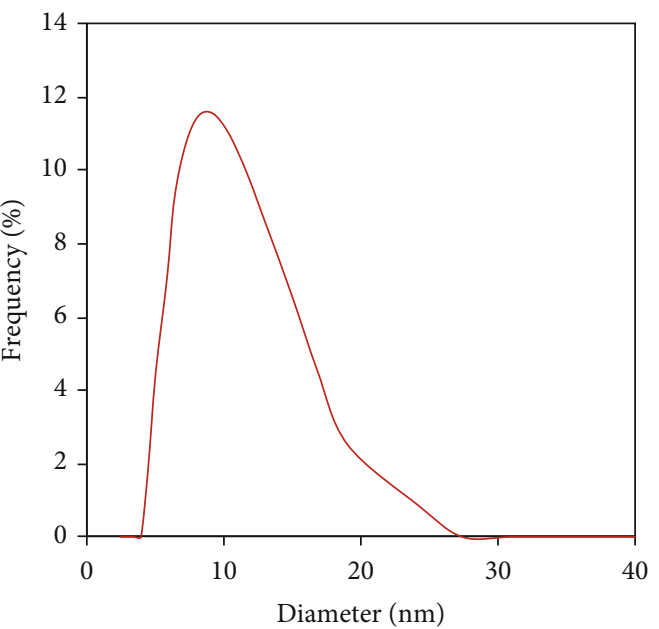

FIgURE 4: Particle size distribution profile of rutin emulsion in water.

nuclear phagocyte system and easily penetrate into the human organs, especially tumors. This is because the size of blood vessels of tumors ranges from 100 to $600 \mathrm{~nm}$. Therefore, the size of nanoparticles less than $100 \mathrm{~nm}$ is optimal for the accumulation of the toxic compounds in the cancer cells [31-33]. Another reason is that the spherical-shaped 


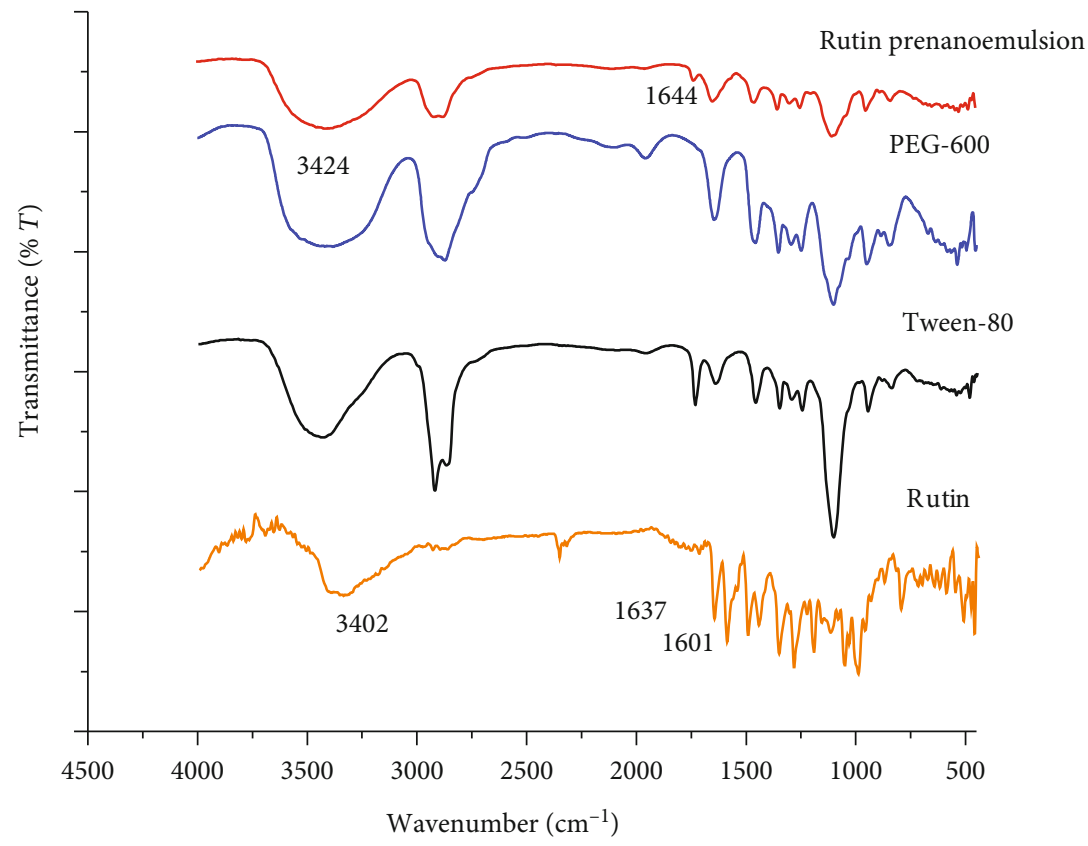

Figure 5: FTIR spectrum of rutin, PEG, Tween, and prenanoemulsion rutin.

nanoparticles have better mobility in the blood vessel than nanoparticles with other shapes. Thus, the prenanoemulsion of rutin as a drug delivery system was proved to be successfully fabricated. The dispersion of the prenanoemulsion system in water has generated rutin nanoparticles with the desired shapes and sizes targeted for enhancing its bioactivity.

The size distribution profile of rutin nanoemulsion is illustrated in Figure 4. It was seen that the distribution of rutin particle is unimodal with narrow distribution having a polydisperse index of 1.5. This suggested that the rutin particles are quite uniform with an average size of $8-15 \mathrm{~nm}$. The size of rutin nanoparticles measured from DLS analysis was similar to that estimated from TEM.

The chemical structure of rutin and its interactions with a mixture of PEG/Tween in the prenanoemulsion with PEG/Tween was investigated by FTIR spectroscopy. Figure 5 shows the FTIR of pure rutin, rutin prenanoemulsion, PEG, and Tween. In the IR spectra of pure rutin, the absorption band at $3402 \mathrm{~cm}^{-1}$ was assigned to $\mathrm{OH}$ groups and $=\mathrm{C}-\mathrm{H}$ bonds in the benzene ring. The absorption band at $1637 \mathrm{~cm}^{-1}$ was assigned to the vibration of the $\mathrm{C}=\mathrm{O}$ bond. Additionally, the absorption band due to the $\mathrm{C}=\mathrm{C}$ bond at $1601 \mathrm{~cm}^{-1}$ verified the presence of the aromatic alkene group. In the IR spectrum of rutin prenanoemulsion, the absorption band at $3424 \mathrm{~cm}^{-1}$ was ascribed for $\mathrm{OH}$ groups and aromatic $\mathrm{C}-\mathrm{H}$ linkages. The absorption band appeared at $2980 \mathrm{~cm}^{-1}$ belonged to the aliphatic $\mathrm{C}-\mathrm{H}$ bond in Tween and PEG. The characteristic absorption band of rutin prenanoemulsion was similar to those of PEG, and Tween and most of the characteristic bands corresponding to rutin did not appear. However, the carbonyl absorption band was shifted from $1637 \mathrm{~cm}^{-1}$ in the FTIR spectrum of rutin to $1644 \mathrm{~cm}^{-1}$ in the FTIR spectrum of rutin prenanoemulsion. The shift in the absorption band may be due to the interactions involving hydrogen bonding between rutin and PEG/Tween mixture.
The interactions probably favour the hydrophilic characteristics of rutin in the prenanoemulsion.

Figure 6 shows the ${ }^{1} \mathrm{H}$-NMR spectrum of rutin prenanoemulsion. In the spectrum, the signal at $4.4 \mathrm{ppm}$ is assigned to the proton of methanol-d4. The group of signals at 3.6$3.7 \mathrm{ppm}$ is the characteristic peaks of PEG. The signals marked with asterisk were assigned to Tween-80. To assign thoroughly the signals of rutin, the rutin prenanoemulsion was acidified with $\mathrm{HCl} 1 \mathrm{M}$ to remove substantial amount of PEG and Tween. The sedimental was collected and subjected to NMR measurement.

Figure 7 presents the ${ }^{1} \mathrm{H}$-NMR spectra of pure rutin and rutin prenanoemulsion after the acidification. It could be seen that after the acidification, most of Tween and PEG were removed, corresponding to the significant decrease in the signal intensity of Tween and PEG. Consequently, the small signals of rutin were observed. The assignment for the signals is given in Figure 7. From the assignments, it confirmed that the chemical structure of rutin was almost preserved in the prenanoemulsion system. Therefore, we could conclude that the formation of prenanoemulsion with the PEG/Tween system did not change the chemical characteristics of rutin.

\subsection{In Vitro Cytotoxicity of the Rutin Prenanoemulsion} System. From the TEM result, the rutin nanoparticle was liberated into the water phase with the size of $15 \mathrm{~nm}$. The efficacy of this drug delivery system could be enhanced due to the small size of active compounds of rutin. The anticancer effects and the safety of rutin prenanoemulsion were investigated through in vitro assay tests. In the in vitro assay, lung cancer cells, colon cancer cells, and human fibroblast cells were treated with various concentrations of pure rutin, rutin prenanoemulsion, and the excipients for 72 hours. The rutin concentration in the prenanoemulsion rutin sample was determined by HPLC with the UV detector. The analysis 


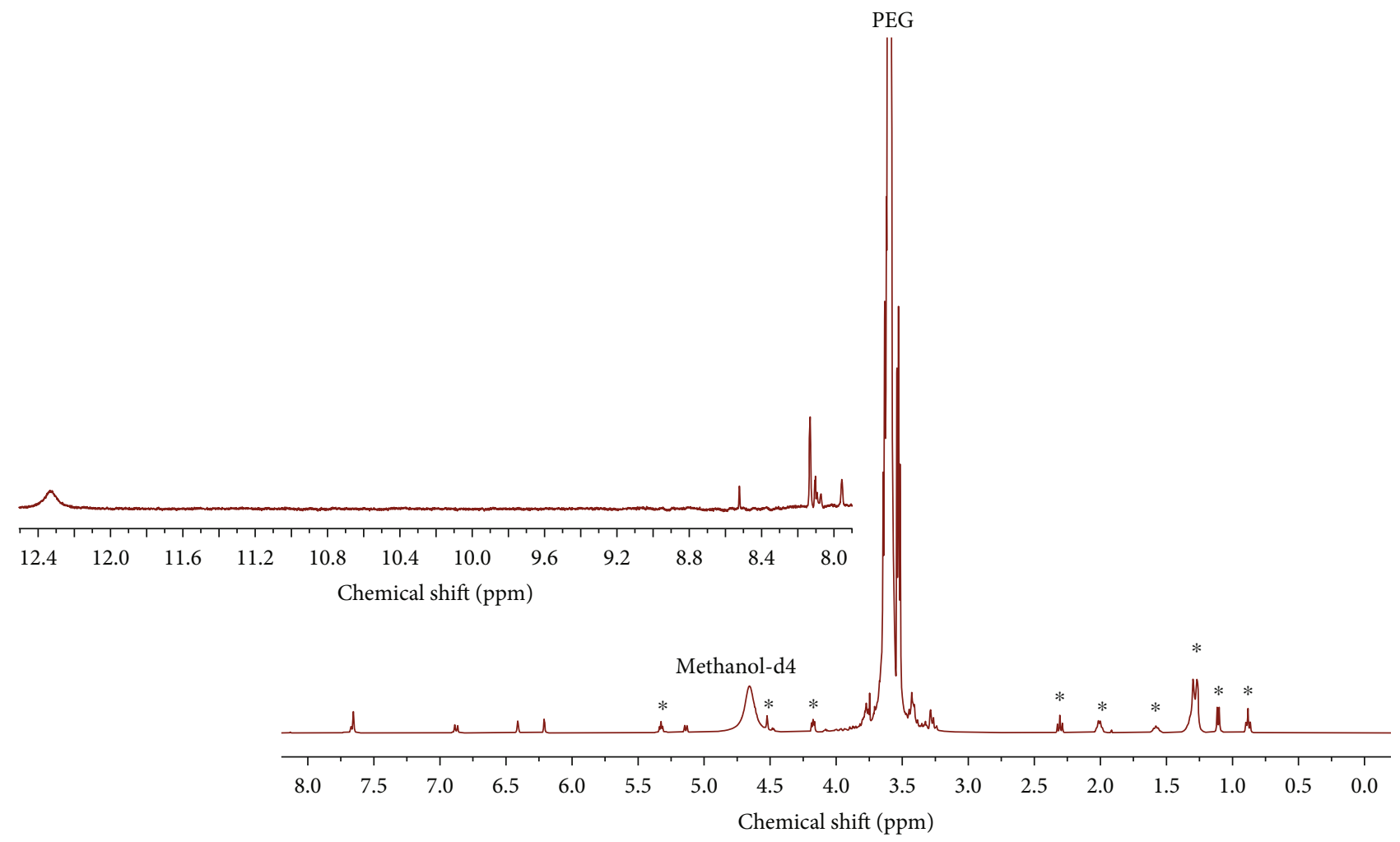

FIGURE 6: ${ }^{1} \mathrm{H}-\mathrm{NMR}$ spectrum of rutin prenanoemulsion $(400 \mathrm{MHz}$, in methanol-d4).

showed that the amount of rutin in the prenanoemulsion is about $9.27 \%$. From this concentration, the rutin prenanoemulsion sample was diluted to various rutin nanoemulsions with the concentration ranges from 30 to $300 \mu \mathrm{M}$ for the MTS assay.

Figure 8 shows the MTS assay test results when lung cancer cells A549 were incubated with pure rutin, rutin nanoemulsion, and the excipients at the concentrations ranging from 30 to $300 \mu \mathrm{M}$ for 72 hours. The reduction in the MTS test indicates the viability and the proliferation of the cells. The results in Figure 8 showed that the living rate of A549 lung cancer cell was remarkably different between the groups of wells supplemented with different reagents (control, pure rutin, rutin nanoemulsion, and excipients) and at different concentrations $\left({ }^{*} p<0.05\right.$ and $\left.{ }^{*} p<0.05\right)$. The viability of A549 lung cancer cells decreased as concentrations of nanoemulsion rutin increased in the range of $100-300 \mu \mathrm{M}$. At the same concentration of $150 \mu \mathrm{M}$, rutin nanoemulsion, pure rutin, and the excipients caused $44.04 \%, 4.65 \%$, and $5.35 \%$ of cell death, respectively. At the concentration of $300 \mu \mathrm{M}$, the rutin nanoemulsion, pure rutin, and excipients, the rate of cell death in the wells was $99.74 \%, 4.4 \%$, and $16.48 \%$, respectively. These results revealed that at the concentration range of $150-300 \mu \mathrm{M}$, the rutin prenanoemulsion caused higher viability in inhibition and proliferation of the A549 lung cancer cells than pure rutin and the excipients.

The IC50 values of pure rutin, rutin nanoemulsion, and the excipients were determined by the rate of survival of A549 lung cancer cells after they were all treated with the studied concentrations. From the MTS assay results, the typical equation describing the correlation between the rate of survival of A549 cells and the corresponding concentration of nanorutin was established as follows:

$$
y=-83.56 \ln (x)+471.32(R 2=0.9654)
$$

in which, $x$ represents the concentration of nanorutin $(\mu \mathrm{M})$ and $y$ represents the percentage of viable cells of sample wells compared to control wells without samples.

From Equation (2), when $y$ value was taken as 50, the IC50 values of nanoemulsion rutin in A549 lung cancer cell line were determined to be $154.8 \mu \mathrm{M}$. On the other hand, Figure 8 shows that the IC50 values of pure rutin and the excipients were higher than $300 \mu \mathrm{M}$. These results indicated that rutin prenanoemulsion can inhibit A549 lung cancer cells from concentrations higher than $150 \mu \mathrm{M}$; pure rutin and the excipients are nontoxic to those cells at concentrations lower than $300 \mu \mathrm{M}$. In the study reported by Goitia et al., the cytotoxicity of the complex $\left(\mathrm{Na}_{2}\left[\mathrm{VO}\right.\right.$ (rutin) $\left.\left.(\mathrm{OH})_{2}\right] \cdot 5 \mathrm{H}_{2} \mathrm{O}\right)$ in A549 lung cancer cells has the IC50 value of $93 \mu \mathrm{M}$ [34]. The IC50 value of the complex was lower than the IC50 value of the rutin prenanoemulsion in this study $(150 \mu \mathrm{M})$. These results indicate that the encapsulation of rutin in PEG/Tween plays an important role in the enhancement of cytotoxic activity. It may be explained that rutin nanoemulsion is well soluble in water. The increased hydrophilic moiety of rutin molecules in the nanoemulsion decreases the energy barrier and subsequently increases the intermembrane transfer rate by over 25-fold [35]. Therefore, the absorption of rutin in PEG into cells is higher than this of pure rutin. 


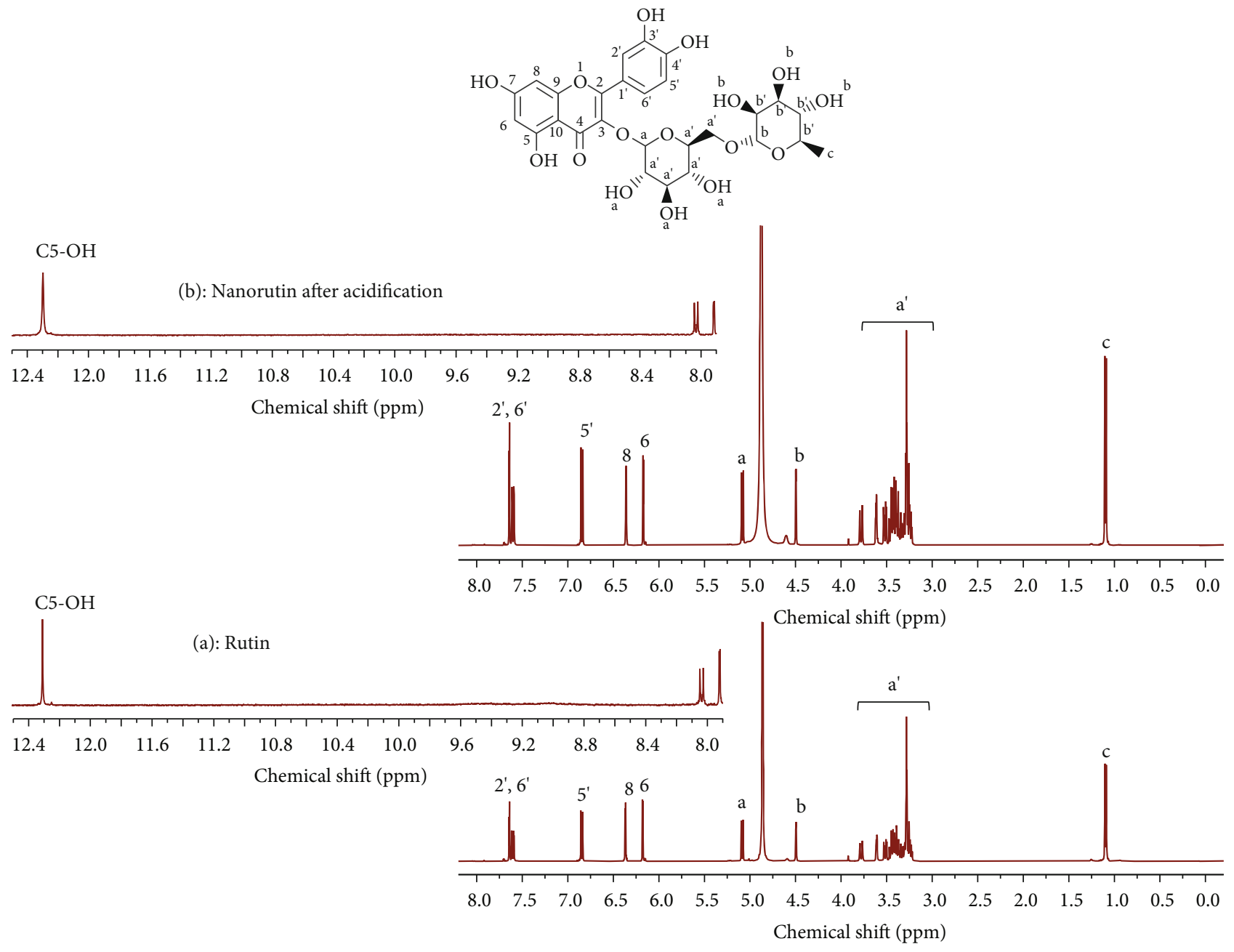

Figure 7: ${ }^{1} \mathrm{H}-\mathrm{NMR}$ of (a) rutin and (b) rutin prenanoemulsion after acidification (400 MHz, in methanol-d4).

To evaluate the cytotoxicity of the rutin prenanoemulsion in the Caco2 colon cancer cells, the assay was prepared in the same way as for the lung cancer cells. These results are shown in Figure 9.

Figure 9 shows the results of the MTS test when Caco2 colon cancer cells were incubated with pure rutin, rutin prenanoemulsion, and the excipients at concentrations in the range of $30-300 \mu \mathrm{M}$ for 72 hours. As similar as the results observed for A549 lung cancer cell, the living rate of Caco2 colon cancer cell was drastically different between the groups of wells supplemented with different reagents (control, pure rutin, rutin prenanoemulsion, and the excipients) and at different concentrations $\left({ }^{*} p<0.05\right.$ and $\left.{ }^{\#} p<0.05\right)$. The rutin prenanoemulsion had a cytotoxic effect on the viability and proliferation of $\mathrm{CacO} 2$ colon cancer cells within the concentration range of $150-500 \mu \mathrm{M}$. However, pure rutin and the excipients exhibited no cytotoxic effect in Caco 2 cells at the concentration of less than $500 \mu \mathrm{M}$. At the concentrations of $500 \mu \mathrm{M}$, the rate of cell death in those wells containing rutin prenanoemulsion, pure rutin, or the excipients compared to the control wells was $82.17 \%, 25.45 \%$, and $36.75 \%$, respectively. From the results of the MTS assay, the general equation describing the correlation between the rate of survival of $\mathrm{Caco} 2$ cells and the corresponding concentration of nanorutin was shown as follows:

$$
y=-44.93 \ln (x)+298.33\left(R^{2}=0.9949\right) .
$$

From Equation (3), the IC50 value of rutin prenanoemulsion in the Caco 2 cell line was $251.5 \mu \mathrm{M}$. The IC50 value of pure rutin and the excipients was higher than $500 \mu \mathrm{M}$. The result demonstrated that the cytotoxic effect of pure rutin and rutin prenanoemulsion depends on the different cell lines (shown in Figure 10). ben Sghaier et al. also reported the similar results of IC50, in which the IC50 values of pure rutin in A549 lung and $\mathrm{Caco} 2$ cancer cells were 559.83 and $710.59 \mu \mathrm{M}$, respectively [36]. These results indicated that pure rutin and rutin prenanoemulsion had higher cytotoxicity to A549 cells than Caco2 cells. Rutin prenanoemulsion is more effective in treating anticancer than pure rutin. It is probably because that rutin prenanoemulsion dissolves in culture medium better than pure rutin. Moreover, with nanosize of rutin particles, i.e., $15 \mathrm{~nm}$, rutin in the prenanoemulsion was easily penetrated through cell membranes. Previous studies have demonstrated that nanoparticles with 


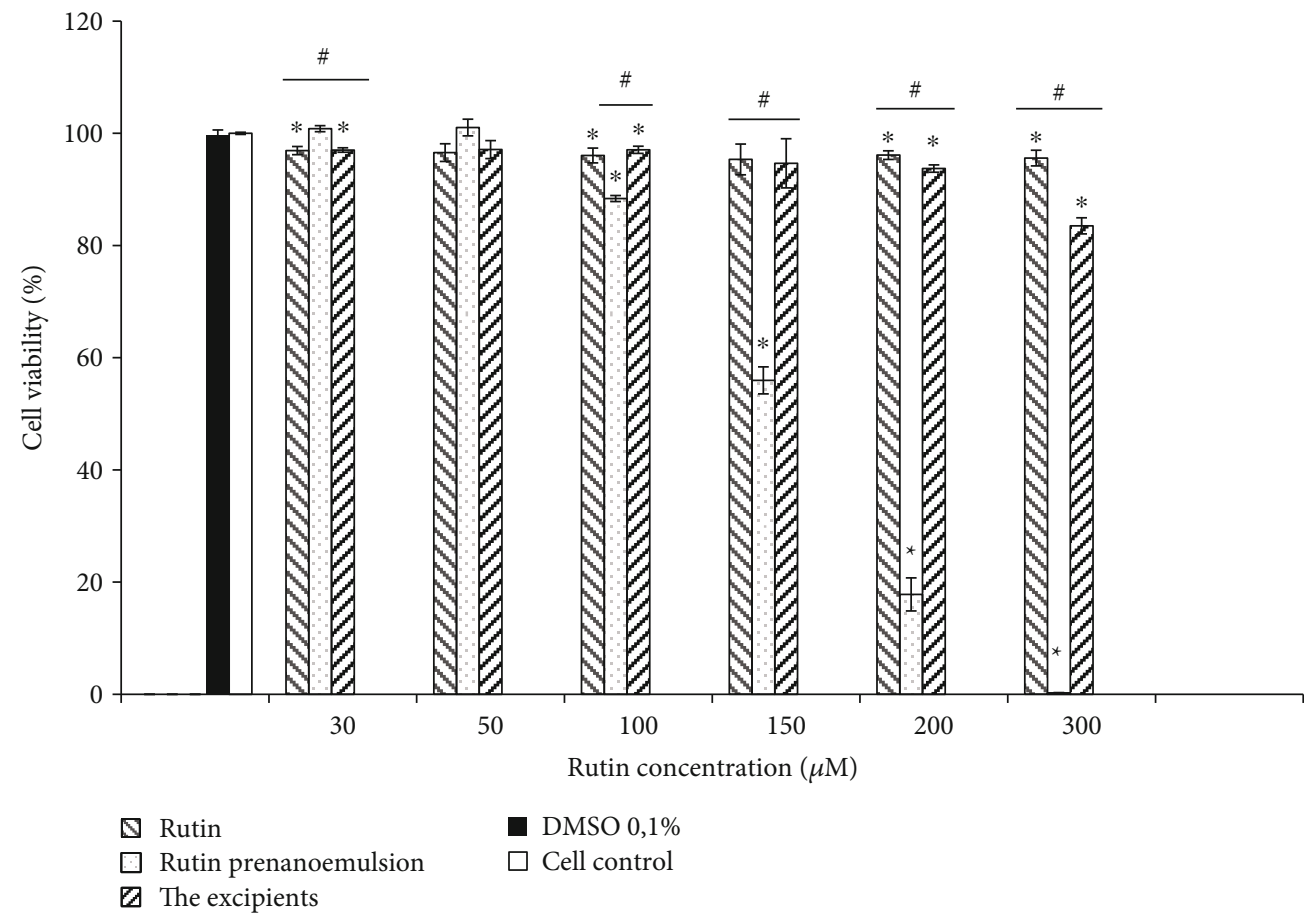

FIGURE 8: Cytotoxicity effects of pure rutin, prenanoemulsion of rutin, and excipients (PEG and Tween 80) to A549 lung cancer cells.

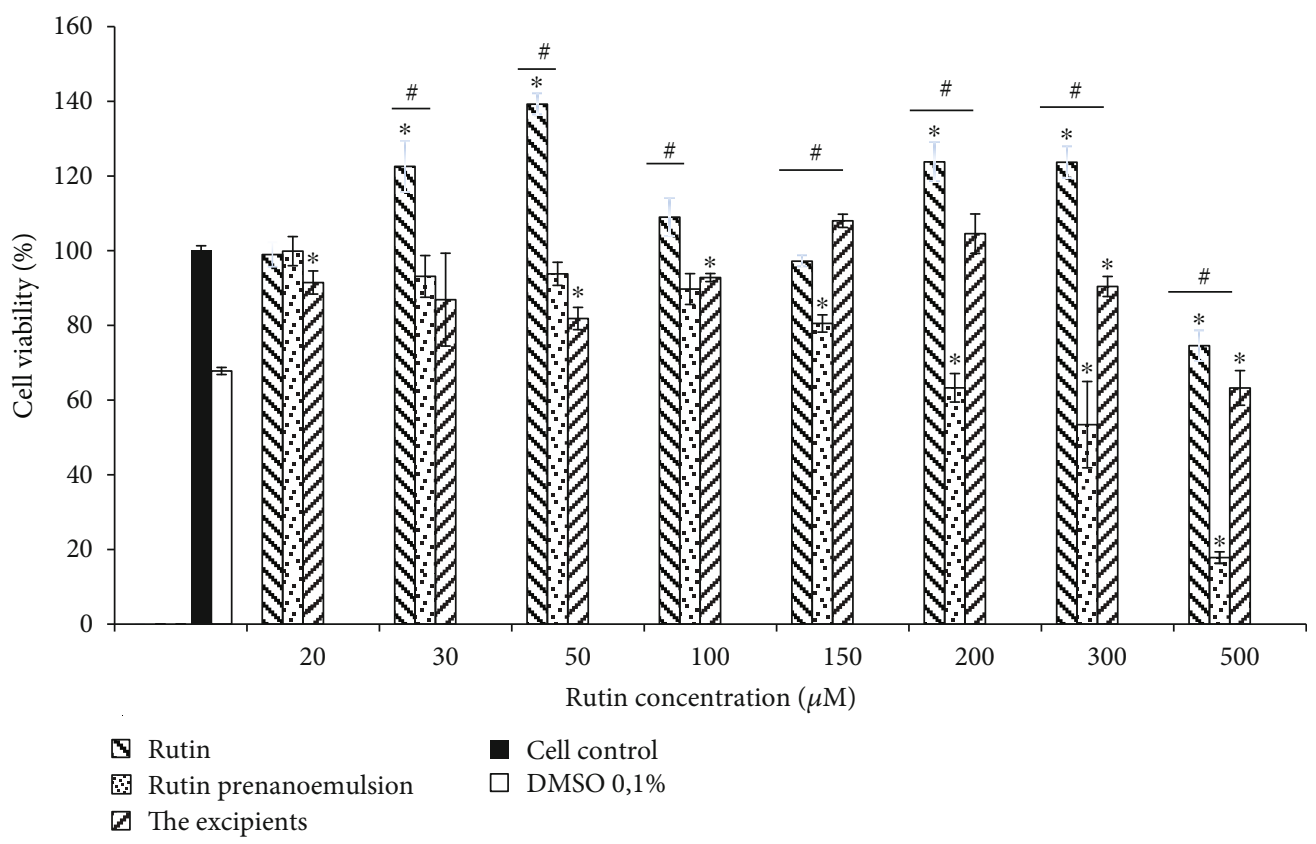

FIGURE 9: Cytotoxicity effects of pure rutin, rutin prenanoemulsion, and the excipients (PEG and Tween-80) to Caco2 colon cancer cells.

size ranging from 10 to $100 \mathrm{~nm}$ are ideal for the drug delivery system to intracellular internalization [37-39]. The bioavailability of rutin in preemulsion with the PEG/Tween mixture has been significantly enhanced. This is because the shortchain length of PEG causes a higher probability of nonspecific protein absorption resulting in a higher uptake of cancer cells [40] and Tween-80 could help to increase the permeability through the cell membrane [41].

The MTS assay of rutin prenanoemulsion and the PEG/Tween mixture in healthy human fibroblast cell line was conducted to assess the safety of the rutin prenanoemulsion. Healthy human fibroblast cells were incubated with 


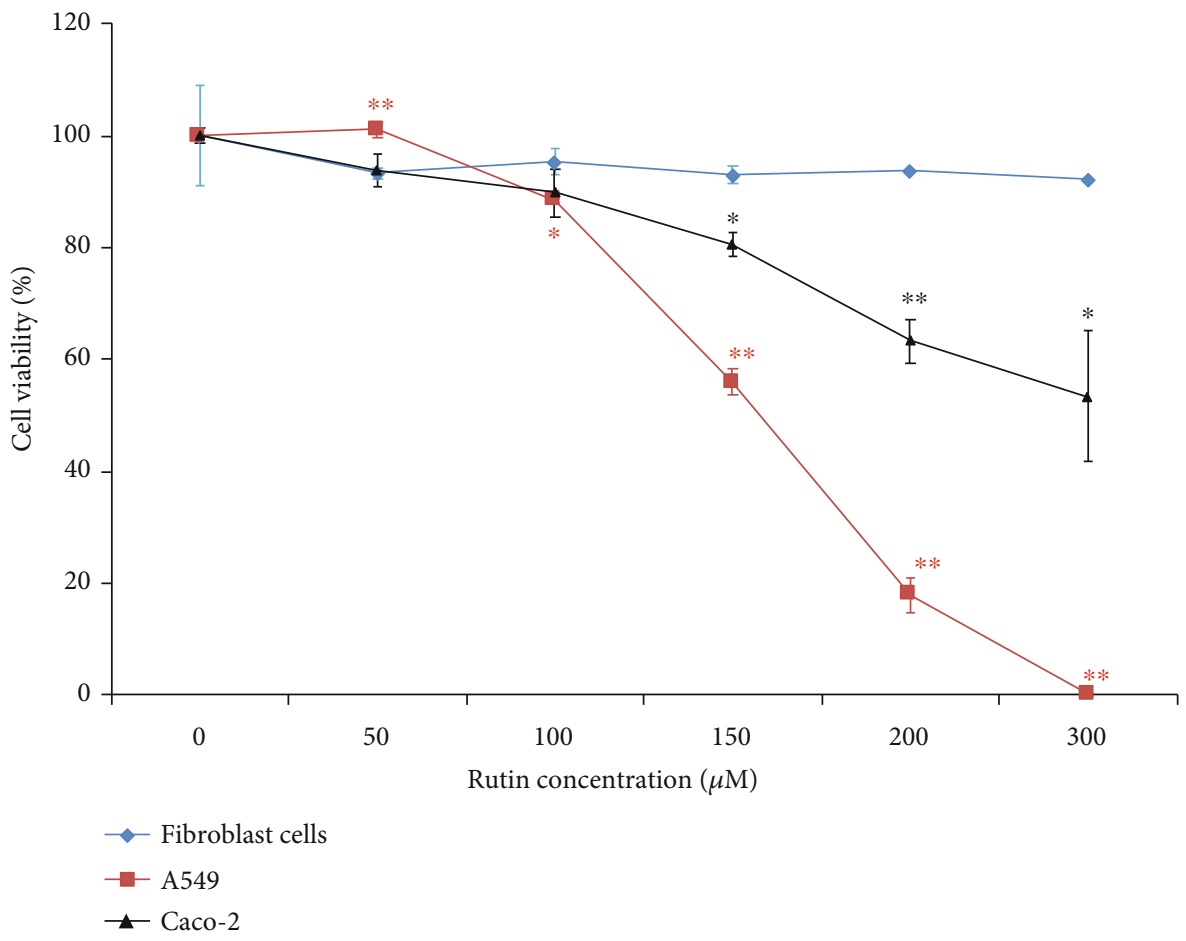

FIGURE 10: Comparing the inhibitory effect of rutin prenanoemulsion in cancer cell lines and healthy cell lines.

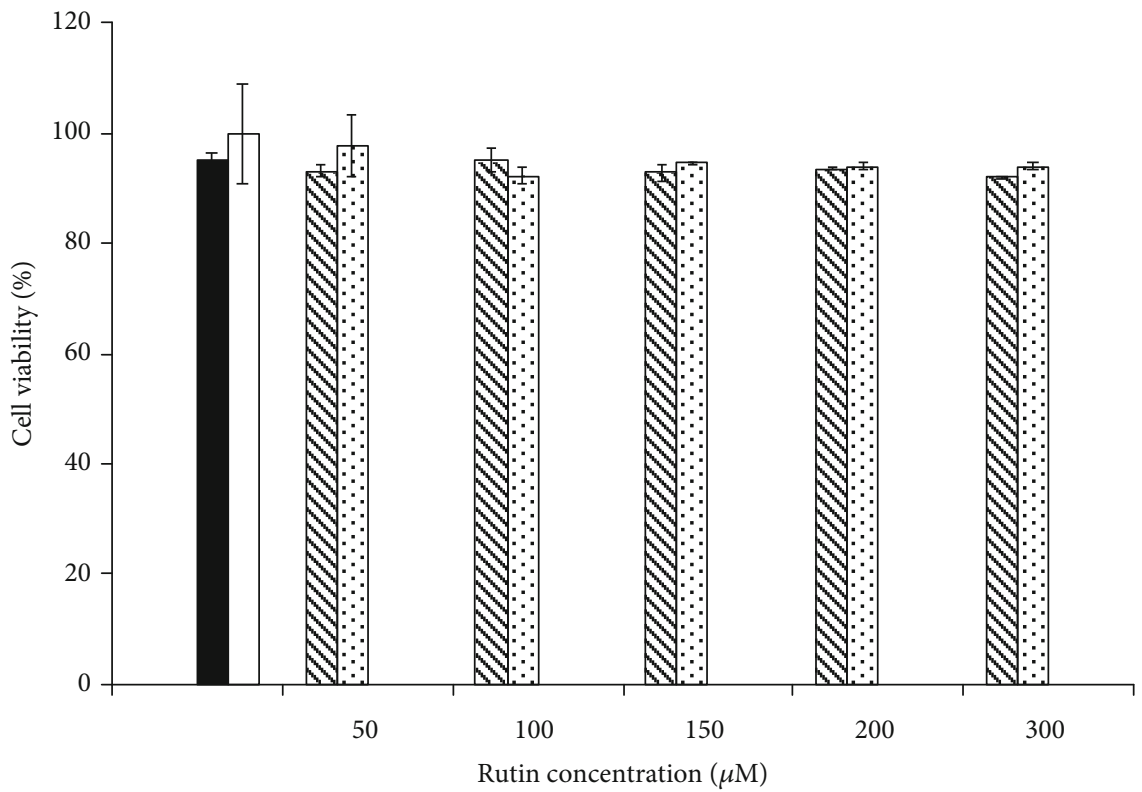

Rutin prenanoemulsion

DMSO 0,1\%

The excipients

$\square$ Cell control

Figure 11: Cytotoxicity effects of rutin prenanoemulsion and the excipients (PEG-600 and Tween-80) to healthy human fibroblast cells.

prenanoemulsion rutin, the mixture PEG/Tween, control vehicle solution, or control solution at a concentration in the range $30-300 \mu \mathrm{M}$ for 72 hours. Figure 11 shows the cytotoxicity effects of rutin prenanoemulsion and the excipi- ents to healthy human fibroblast cells. It showed that rutin prenanoemulsion and the PEG/Tween mixture had no cytotoxic effects on fiber cells at the concentrations less than $300 \mu \mathrm{M}$. The results revealed that in the concentration range 
of $100-300 \mu \mathrm{M}$, the rutin prenanoemulsion inhibited viability and proliferation of the cancer cells but showed the safety for normal cells.

\section{Conclusions}

The preparation of rutin prenanoemulsion was successfully made in this work. Rutin in the prenanoemulsion had a spherical shape with a size of $15 \mathrm{~nm}$. The rutin prenanoemulsion showed good solubility in water. The chemical structure of rutin was unmodified in the prenanoemulsion system with PEG/Tween and subsequently preserved its bioactivities. When rutin was formed in the prenanoemulsion system with a small size, the rutin's bioactivity was enhanced double. The IC50 of rutin in prenanoemulsion was determined to be $154.8 \mu \mathrm{M}$ for A549 cancer cell treatment and $251.5 \mu \mathrm{M}$ for Caco-2 cancer cell treatment. It reveals that the formation of the rutin prenanoemulsion has potential to become a new formulation which stabilizes the rutin and increases its bioactivity towards cancer diseases.

\section{Data Availability}

The data used to support the findings of this study are available from the corresponding author upon request.

\section{Conflicts of Interest}

The authors declare that there is no conflict of interest regarding the publication of this paper.

\section{Acknowledgments}

This research is funded by Hanoi University of Science and Technology (HUST) under Grant number T2018-PC-098. The authors would like to acknowledge Ms. Dao Thu Thao (Institute of Biotechnology, Vietnam Academy of Science and Technology) for her kind support with in vitro analysis.

\section{References}

[1] J. B. Harborne, "Nature, distribution, and function of plant flavonoids," Progress in Clinical and Biological Research, vol. 213, pp. 15-24, 1986.

[2] J. P. Lin, J. S. Yang, J. J. Lin et al., "Rutin inhibits human leukemia tumor growth in a murine xenograft model in vivo," Environmental Toxicology, vol. 27, no. 8, pp. 480-484, 2012.

[3] H. Chen, Q. Miao, M. Geng et al., "Anti-tumor effect of rutin on human neuroblastoma cell lines through inducing G2/M cell cycle arrest and promoting apoptosis," The Scientific World Journal, vol. 2013, 8 pages, 2013.

[4] C. Martínez Conesa, V. Vicente Ortega, M. J. Yáñez Gascón et al., "Treatment of metastatic melanoma B16F10 by the flavonoids tangeretin, rutin, and diosmin," Journal of Agricultural and Food Chemistry, vol. 53, no. 17, pp. 6791-6797, 2005.

[5] J. Cristina Marcarini, M. S. Ferreira Tsuboy, R. Cabral Luiz, L. Regina Ribeiro, C. Beatriz Hoffmann-Campo, and M. Ségio Mantovani, "Investigation of cytotoxic, apoptosisinducing, genotoxic and protective effects of the flavonoid rutin in HTC hepatic cells," Experimental and Toxicologic Pathology, vol. 63, no. 5, pp. 459-465, 2011.
[6] J. R. Araújo, P. Gonçalves, and F. Martel, "Chemopreventive effect of dietary polyphenols in colorectal cancer cell lines," Nutrition Research, vol. 31, no. 2, pp. 77-87, 2011.

[7] M. R. Lauro, M. L. Torre, L. Maggi, F. de Simone, U. Conte, and R. P. Aquino, "Fast- and slow-release tablets for oral administration of flavonoids: rutin and quercetin," Drug Development and Industrial Pharmacy, vol. 28, no. 4, pp. 371-379, 2002.

[8] X. Liu, D. Tang, X. Yin, Y. Gao, Y. Wei, and Y. Chen, "Pharmacokinetic study of rutin in normal and diabetic nephropathy rats," Acta Academiae Medicinae Xuzhou, vol. 29, pp. 708712, 2009.

[9] R. Mauludin, R. H. Müller, and C. M. Keck, "Development of an oral rutin nanocrystal formulation," International Journal of Pharmaceutics, vol. 370, no. 1-2, pp. 202-209, 2009.

[10] J. S. Almeida, F. Lima, S. D. Ros, L. O. S. Bulhões, L. M. Carvalho, and R. C. R. Beck, "Nanostructured systems containing rutin: in vitro antioxidant activity and photostability studies," Nanoscale Research Letters, vol. 5, no. 10, pp. 16031610, 2010.

[11] P. Kumar and A. K. P. Bhopal, "Formulation design and evalution of rutin loaded selfemulsifying drug delivary system (SEDDs) using edible oil," Asian Journal of Pharmaceutical and Clinical Research, vol. 5, no. 1, pp. 76-78, 2012.

[12] L. Banjare and N. Ghillare, "Development of biocompatible nanoparticles for sustained topical delivery of Rutin," International journal of pharmaceutical and biological archives, vol. 3, no. 2, pp. 326-332, 2012.

[13] R. Kamel, M. Basha, and S. H. Abd El-Alim, "Development of a novel vesicular system using a binary mixture of sorbitan monostearate and polyethylene glycol fatty acid esters for rectal delivery of rutin," Journal of Liposome Research, vol. 23, no. 1, pp. 28-36, 2013.

[14] Z. Hooresfand, S. Ghanbarzadeh, and H. Hamishehkar, "Preparation and characterization of rutin-loaded nanophytosomes," Pharmaceutical Sciences, vol. 21, no. 3, pp. 145-151, 2015.

[15] K. V. Sri, A. Kondaiah, J. V. Ratna, and A. Annapurna, "Preparation and characterization of quercetin and rutin cyclodextrin inclusion complexes," Drug Development and Industrial Pharmacy, vol. 33, no. 3, pp. 245-253, 2008.

[16] T. A. Nguyen, B. Liu, J. Zhao, D. S. Thomas, and J. M. Hook, "An investigation into the supramolecular structure, solubility, stability and antioxidant activity of rutin/cyclodextrin inclusion complex," Food Chemistry, vol. 136, no. 1, pp. 186-192, 2013.

[17] G. K. In and J. Nieva, "Emerging chemotherapy agents in lung cancer: nanoparticles therapeutics for non-small cell lung cancer," Translational Cancer Research, vol. 4, no. 4, pp. 340-355, 2015.

[18] G. Wang and H. Uludag, "Recent developments in nanoparticle-based drug delivery and targeting systems with emphasis on protein-based nanoparticles," Expert Opinion on Drug Delivery, vol. 5, no. 5, pp. 499-515, 2008.

[19] E. A. Mahmoud, E. R. Bendas, and M. I. Mohamed, "Preparation and evaluation of self-nanoemulsifying tablets of carvedilol," AAPS PharmSciTech, vol. 10, no. 1, pp. 183-192, 2009.

[20] C. W. Pouton, "Formulation of poorly water-soluble drugs for oral administration: physicochemical and physiological issues and the lipid formulation classification system," European Journal of Pharmaceutical Sciences, vol. 29, no. 3-4, pp. 278$287,2006$. 
[21] M. Ahmad, Sahabjada, J. Akhtar et al., "Development of a new rutin nanoemulsion and its application on prostate carcinoma PC3 cell line," EXCLI Journal, vol. 16, pp. 810-823, 2017.

[22] G. Kaur and S. K. Mehta, "Developments of polysorbate (Tween) based microemulsions: preclinical drug delivery, toxicity and antimicrobial applications," International Journal of Pharmaceutics, vol. 529, no. 1-2, pp. 134-160, 2017.

[23] N. Watrous-Peltier, J. Uhl, V. Steel, L. Brophy, and E. MeriskoLiversidge, "Direct suppression of phagocytosis by amphipathic polymeric surfactants," Pharmaceutical Research, vol. 9, no. 9, pp. 1177-1183, 1992.

[24] X. Tao, Y. Li, Q. Hu et al., "Preparation and drug release study of novel nanopharmaceuticals with polysorbate 80 surface adsorption," Journal of Nanomaterials, vol. 2018, Article ID 4718045, 2018.

[25] M. F. Tai, C. W. Lai, and S. B. Abdul Hamid, "Facile synthesis polyethylene glycol coated magnetite nanoparticles for high colloidal stability," Journal of Nanomaterials, vol. 2016, Article ID 8612505, 7 pages, 2016.

[26] S. Georgeta, P. Pana, H. Tunde, and B. Sanda, "The isolation and identification of rutin from pharmaceutical products. An. Univ. Oradea Fasc," in Ecotoxicol. Zooteh. Tehnol. Ind, pp. 109-113, Aliment, 2016.

[27] V. B. Borhade, H. A. Nair, and D. D. Hegde, "Development and characterization of self-microemulsifying drug delivery system of tacrolimus for intravenous administration," Drug Development and Industrial Pharmacy, vol. 35, no. 5, pp. 619-630, 2009.

[28] S.-x. Cui, S.-f. Nie, L. Li, C.-g. Wang, W.-s. Pan, and J.-p. Sun, "Preparation and evaluation of self-microemulsifying drug delivery system containing vinpocetine," Drug development and industrial pharmacy, vol. 35, no. 5, pp. 603-611, 2009.

[29] G. Eccleston, J. Swarbrick, and J. Boylan, Encyclopedia of Pharmaceutical Technology, Swarbric I, 1994.

[30] C. Pang, J. Y. Jung, J. W. Lee, and Y. T. Kang, "Thermal conductivity measurement of methanol-based nanofluids with $\mathrm{Al} 2 \mathrm{O} 3$ and $\mathrm{SiO} 2$ nanoparticles," International Journal of Heat and Mass Transfer, vol. 55, no. 21-22, pp. 5597-5602, 2012.

[31] H. Maeda and Y. Matsumura, "Tumoritropic and lymphotropic principles of macromolecular drugs," Critical Reviews in Therapeutic Drug Carrier Systems, vol. 6, no. 3, pp. 193-210, 1989.

[32] F. Yuan, M. Dellian, D. Fukumura et al., "Vascular permeability in a human tumor xenograft: molecular size dependence and cutoff size," Cancer Research, vol. 55, no. 17, pp. 37523756, 1995.

[33] H. Maeda, "Macromolecular therapeutics in cancer treatment: the EPR effect and beyond," Journal of Controlled Release, vol. 164, no. 2, pp. 138-144, 2012.

[34] H. Goitia, P. Quispe, L. G. Naso et al., "Interactions of rutin with the oxidovanadium (iv) cation. Anticancer improvement effects of glycosylated flavonoids," New Journal of Chemistry, vol. 43, no. 45, pp. 17636-17646, 2019.

[35] J. R. Silvius and M. J. Zuckermann, "Interbilayer transfer of phospholipid-anchored macromolecules via monomer diffusion," Biochemistry, vol. 32, no. 12, pp. 3153-3161, 2002.

[36] M. b. Sghaier, A. Pagano, M. Mousslim, Y. Ammari, H. Kovacic, and J. Luis, "Rutin inhibits proliferation, attenuates superoxide production and decreases adhesion and migration of human cancerous cells," Biomedicine \& Pharmacotherapy, vol. 84, pp. 1972-1978, 2016.
[37] H. S. Choi, W. Liu, P. Misra et al., "Renal clearance of quantum dots," Nature Biotechnology, vol. 25, no. 10, pp. 1165-1170, 2007.

[38] G. Gaucher, M. H. Dufresne, V. P. Sant, N. Kang, D. Maysinger, and J. C. Leroux, "Block copolymer micelles: preparation, characterization and application in drug delivery," Journal of Controlled Release, vol. 109, no. 1-3, pp. 169188, 2005.

[39] A. Aderem and D. M. Underhill, "Mechanisms of phagocytosis in macrophages," Annual Review of Immunology, vol. 17, no. 1, pp. 593-623, 1999.

[40] C. Cruje and D. Chithrani, "Polyethylene glycol density and length affects nanoparticle uptake by cancer cells," Journal of Nanomedicine Research, vol. 1, no. 1, 2014.

[41] H. Riehm and J. L. Biedler, "Potentiation of drug effect by Tween 80 in Chinese hamster cells resistant to actinomycin D and daunomycin," Cancer Research, vol. 32, no. 6, pp. 1195-1200, 1972. 